\title{
ОСОБЕННОСТИ МИКРОБИОТЫ ПОЛОСТИ РТА БОЛЬНЫХ С ХРОНИЧЕСКИМ ГЕНЕРАЛИЗОВАННЫМ ПАРОДОНТИТОМ У ЖИТЕЛЕЙ ТВЕРСКОГО РЕГИОНА
}

\begin{abstract}
\begin{tabular}{||r|r} 
FEATURES OF THE ORAL \\
MICROBIOTA OF PATIENTS WITH \\
CHRONIC GENERALIZED PERIODONTIS \\
IN RESIDENTS OF THE TVERSKY REGION \\
v. Chervinets \\
Yu. Chervinets \\
Leont'eva A. \\
v. Belyaev \\
N. Stulov \\
A. Rodionov \\
A. Chervinets \\
A. Troshin \\
v. Rumyantsev
\end{tabular}
Summary. It was analized the spectrum, frequency of occurrence and the number of oral microbiota of the residents of the Tver region: healthy and patients with chronic generalized periodontitis of moderate severity in the period of remission were analyzed. Material was collected and analyzed from 4 biotopes: dental plaque, scraping from the mucous membrane of the dorsum of the tongue, oral fluid and the contents of the gingival groove or the contents of the periodontal pocket. In all biotopes, classical periodontopathogens were not identified, but the appearance of Streptococcus agalactiae was noted in $40-65 \%$ of cases ( $p=0.003)$ in the amount of $3-7.5 \mathrm{lg}$ CFU / $\mathrm{ml}(p=$ 0.024). Dysbiotic changes were not revealed in the content of dental plaque. In scraping from the tongue, in most cases, representatives of the commensal microbiota, Lactobacillus spp. and Peptostreptocossus spp. Streptocossus spp. were found in the parodontal pocket. and Peptostreptocossus spp. in $80 \%$ of cases, Streptococcus agalactiae in $45 \%$, Peptocossus spp. - 40\%. In the oral fluid of people with periodontitis, an increase in the incidence of representatives of Bacillus spp. was noted almost in 13 times.
\end{abstract}

Keywords: chronic generalized periodontitis, microbiota, oral cavity, dysbiosis.

\author{
Червинец Вячеслав Михайлович \\ Д.м.н., профессор, ФГБОУВО Тверской ГМУ Минздрава \\ Poсcuи, г. Тверь \\ chervinets@mail.ru \\ Червинец Юлия Вячеславовна \\ Д.м.н., профессор, ФГБОУ ВО Тверской ГМУ Минздрава \\ Pоссии, г. Тверь \\ julia_chervinec@mail.ru \\ Леонтьева Аурелия Валерьевна \\ Ассистент, ФГБОУ ВО Тверской ГМУ Минздрава \\ России, г. Тверь \\ aurica171900@mail.ru \\ Беляев Всеволод Станиславович \\ ФГБОУ ВО Тверской ГМУ Минздрава России, г. Тверь \\ seva.belyaev.99@mail.ru \\ Стулов Никита Михайлович \\ ФГБОУ ВО Тверской ГМУ Минздрава России, г. Тверь \\ nikita888033@mail.ru \\ Родионов Андрей Александрович \\ К.м.н., дочент, ФГБОУ ВО Тверской ГМУ Минздрава \\ Pоссии, г. Тверь \\ andrew.rodionov@tvergma.ru \\ Червинец Алина Вячеславовна \\ Врач-ортодонт, ООО «Браво», г. Кимры \\ lina555_90@mail.ru \\ трошин Андрей Валерьевич \\ Директор, ООО «Браво», г. Кимры \\ bravostom@mail.ru \\ Румянцев Виталий Анатольевич \\ Д.м.н., профессор, ФГБОУ ВО Тверской ГМУ Минздрава \\ Pоссии, г. Тверь \\ rumyancev_v@tvergma.ru
}

Аннотация. Проанализирован спектр, частота встречаемости и количество микробиоты полости рта жителей Тверской области, здоровых и больных хроническим генерализованным пародонтитом средней степени тяжести в период ремиссии. Материал был собран и проанализирован из 4 биотопов: зубной налёт, соскоб со слизистой оболочки спинки языка, ротовая жидкость, а также содержимое зубодесневого желобка или содержимое пародонтального кармана. Во всех биотопах не были выделены классические пародонтопатогены, но выделены Streptococcus agalactiae в 40-65\% случаев $(p=0,003)$ в количестве $3-7,5 \lg \mathrm{KOE} / \mathrm{Mл}(\mathrm{p}=0,024)$. В содержимом зубного налёта дисбиотические изменения не выявлены. В соскобе с языка в большинстве случаев выделялись представители комменсальной микробиоты - Lactobacillus spp. и Peptostreptococcus spp. В пародонтальном кармане выявлены Streptococcus spp. и Peptostreptococcus spp в 80\% случаев, Streptococcus agalactiae — в 45\%, Peptococcus spp.— в 40\%. В ротовой 


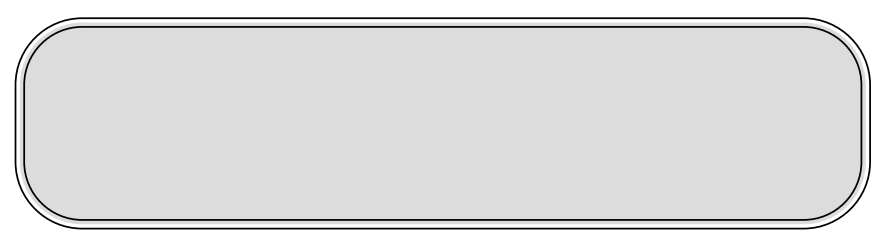

\section{Ввемение}

$\Pi$ олость рта по составу микробиологических сообществ представляет сложную и богатую в видовом плане (более 700 видов) систему, изменения в которой способны оказывать влияние не только на здоровье полости рта, но и всего организма в целом. [1]. Стоматологические заболевания многими авторами рассматриваются в контексте изменения состава биоплёнок [2,3]. Состав биоплёнок влияет на развитие таких заболеваний, как пародонтит, гингивит, кариес и др. [4]; отмечен комменсализм бактерий биоплёнок, который связан с передачей сигнальных молекул в сообществе $[5,6]$.

Многие авторы $[2,3,4,5,6,7]$ связывают хронический пародонтит (ХП) с дисбиозом различных биотопов полости рта, самым важным из которых является пародонтальный карман. С развитием периодонтита могут быть связаны мутации, определяющие чувствительность тканей пародонта к колонизации специфическими микроорганизмами [7]. В результате комплексного исследования выяснено, что некоторые мутантные аллели связаны с уменьшением Tannerella forsythia, Actinomyces gerencseriae, Fusobacterium periodonticum, Prevotella nigrescens, другие сувеличением Porphyromonas gingivalis - ключевого парадонтопатогена [8]. Изучен микробиом щеки и пародонтального кармана при различных видах периодонтитов [9]. Среди обнаруженных 195 родов, наиболее часто встречались стрептококки и неспоробразующие анаэробы [10]. Проведён комплексный анализ-сравнение микробиоты языка, слюны, пародонтального кармана, десневого сосочка [11]. В микробиоте языка преобладали бактерии родов Streptococcus, Prevotella, Veillonella, в микробиоте слюны Streptococcus, Veillonella, пародонтального кармана - Porphyromonas, Fusobacterium, десневом сосочке - Streptococcus, Capnocytophaga, Leptotrichia. Однако в разных регионах могут быть особенности как в качественном, так и в количественном составе микрофлоры полости рта.

\section{Шель исслеАования}

Провести сравнительный анализ микробиоты полости рта здоровых людей и больных хроническим генерализованным парадонтитом у жителей Тверского региона. жидкости у людей, больных пародонтитом отмечено увеличение встречаемости представителей Bacillus spp. почти в 13 раз.

Ключевые слова: хронический генерализованный пародонтит, микробиота, полость рта, дисбиоз.

\section{Материа^ и методы}

Опытная группа (1 группа) - 20 больных с хроническим генерализованным пародонтитом средней степени тяжести в период ремиссии. Из них 14 женщины и 6 мужчин. В здоровой группе исследовано 18 человек (2 группа). Из них 9 лиц женского пола и 9 мужского. Средний возраст исследуемых людей составил 35-45лет.

Исследуемый материал - зубодесневой налёт с вестибулярной поверхности резцов нижней челюсти, соскоб со слизистой оболочки спинки языка площадью $1 \mathrm{~cm}^{2}$, содержимое зубодесневого желобка с одного резца нижней челюсти (только у здоровой группы) или содержимое пародонтального кармана с одного резца нижней челюсти, взятое с помощью бумажного штифта (только у больных пародонтитом) и ротовая жидкость объёмом 1 мл. Материал с поверхности слизистой оболочки брали стерильным ватным тампоном.

Во всех обследуемых группах материал забирали утром (8-9 час) до приёма пищи, помещали в транспортную среду Эймса (Amies) без угля. Ротовую жидкость собирали в стерильные пробирки. В бактериологическую лабораторию материал доставляли в течение 2-х часов. Для выделения факультативно-анаэробных и аэробных бактерий использованы среды - Эндо для энтеробактерий, маннит-солевой агар (М118) для стафилококков, для выявления лецитиназной активности - агар Бэрда-Паркера, М 304 - стрептококковый агар, МPC - лактоагар, Сабуро декстроза агар, Колумбия кровяной агар, хромогенные среды для выявления грибов рода Candida, стрептококков и энтерококков (HiMedia). Для культивирования анаэробов использовали среды бифидоагар и кровяной Шедлера агар. Анаэробные условия создавались в анаэростатах при помощи газогенераторных пакетов BBL. Культивирование проводили при температуре $37^{\circ} \mathrm{C}$ в течение 24-48 час. Количество колоний выражали в $\mathrm{lg} \mathrm{KOE/ \textrm {cm } ^ { 2 }}$ или $\operatorname{lg~KOE/мл.~Идентификация~осуществлялась~по~био-~}$ химической активности с применением API систем (bioMérieux).

Данные экспериментов обрабатывались с помощью прикладной программы «Биостат». Статистическую обработку результатов проводили с использованием критерия Стьюдента, различия считали достоверными при $\mathrm{p}<0,05$. 


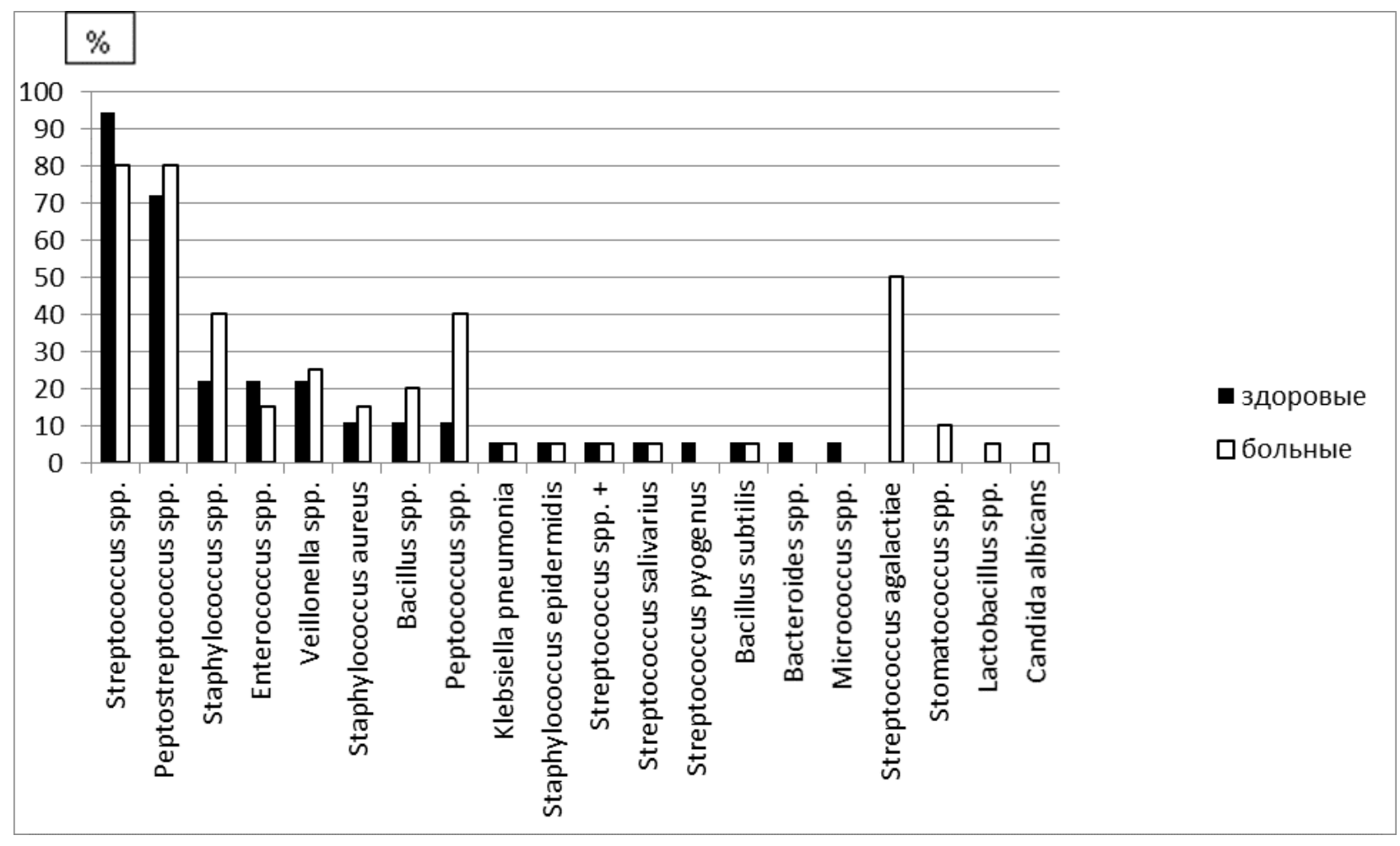

Рис. 1. Сравнительный анализ спектра и частоты встречаемости микроорганизмов зубного налета здоровых исследуемых и больных с пародонтитом. *- данные статистически значимы $(p<0,05)$

\section{Результаты}

Из содержимого зубного налёта здоровых исследуемых (рис. 1) обнаружены Streptococcus spp. в 94,4\% случаев, Peptostreptococcus spp.- в 72,2\%, Staphylococcus spp., Enterococcus spp., Veillonella spp. - в 22,2\%, Staphylococcus aureus, Bacillus spp., Peptococcus spp. - в 11,1\%. Остальные микроорганизмы, Klebsiella pneumoniae, Staphylococcus epidermidis, Streptococcus salivarius, Streptococcus pyogenes, Bacillus subtilis, Bacteroides spp., Micrococcus spp., встречались в менее $10 \%$.

Из содержимого зубного налёта больных пародонтитом (рис. 1) выделены Streptococcus spp. в $80 \%$ случаев, Peptostreptococcus spp. и Streptococcus agalactiaeв 50\%, Staphylococcus spp. и Peptococcus spp. 一 в 40\%, Veillonella spp.— в 25\%, Bacillus spp.- в 20\%, Enterococcus spp. и Staphylococcus aureus - в 15\%. Остальные микроорганизмы, Klebsiella pneumoniae, Staphylococcus epidermidis, Streptococcus salivarius, Bacillus subtilis, Stomatococcus spp., Lactobacillus spp., Candida albicans, встречались в $\leq 10 \%$ случаев.

В соскобе с языка здоровых людей (рис. 2) выявлены Streptococcus spp. в 94,4\% случаев, Peptostreptococcus spp.— B 66,7\%, Staphylococcus aureus - в 55,55\%, Bacillus spp.-27,8\%, Staphylococcus spp., Staphylococcus epidermidis u Veillonella spp.— в 22,2\%, Enterococcus spp., Candida albicansв 16,7\%, Streptobacillus, Micrococcus spp. u Peptococcus spp.- в 11,1\%. Остальные микроорганизмы, Klebsiella pneumoniae, Proteus spp., Streptococcus salivarius, Lactobacillus spp., Clostridium spp., встречались в менее $10 \%$.

В соскобе с языка больных пародонтитом (рис. 2) выделялись Peptostreptococcus spp. в 95\% случаев, Streptococcus spp.- 79\%, Streptococcus agalactiae - в 65\%, Staphylococcus spp.- в 30\%, Bacillus spp., Lactobacillus spp. - в 20\%, Staphylococcus aureus, Enterococcus spp.- в 15\%. Остальные микроорганизмы, Streptobacillus, Bacillus subtilis, Stomatococcus spp., Staphylococcus epidermidis, Veillonella spp., Micrococcus spp. встречались в $\leq 10 \%$ случаев.

Из содержимого зубодесневого желобка здоровых людей (рис. 3) выделялись Streptococcus spp. - 94,4\% случаев, Peptostreptococcus spp. - в 77,8\%, Bacillus spp.- - 44,4\%, Peptococcus spp.- в 38,9\%, Enterococcus spp. - в 22,2\%, Staphylococcus spp., Staphylococcus aureus, Streptococcus salivarius, Veillonella spp.в 11,1\%. Остальные микроорганизмы Streptobacillus, 


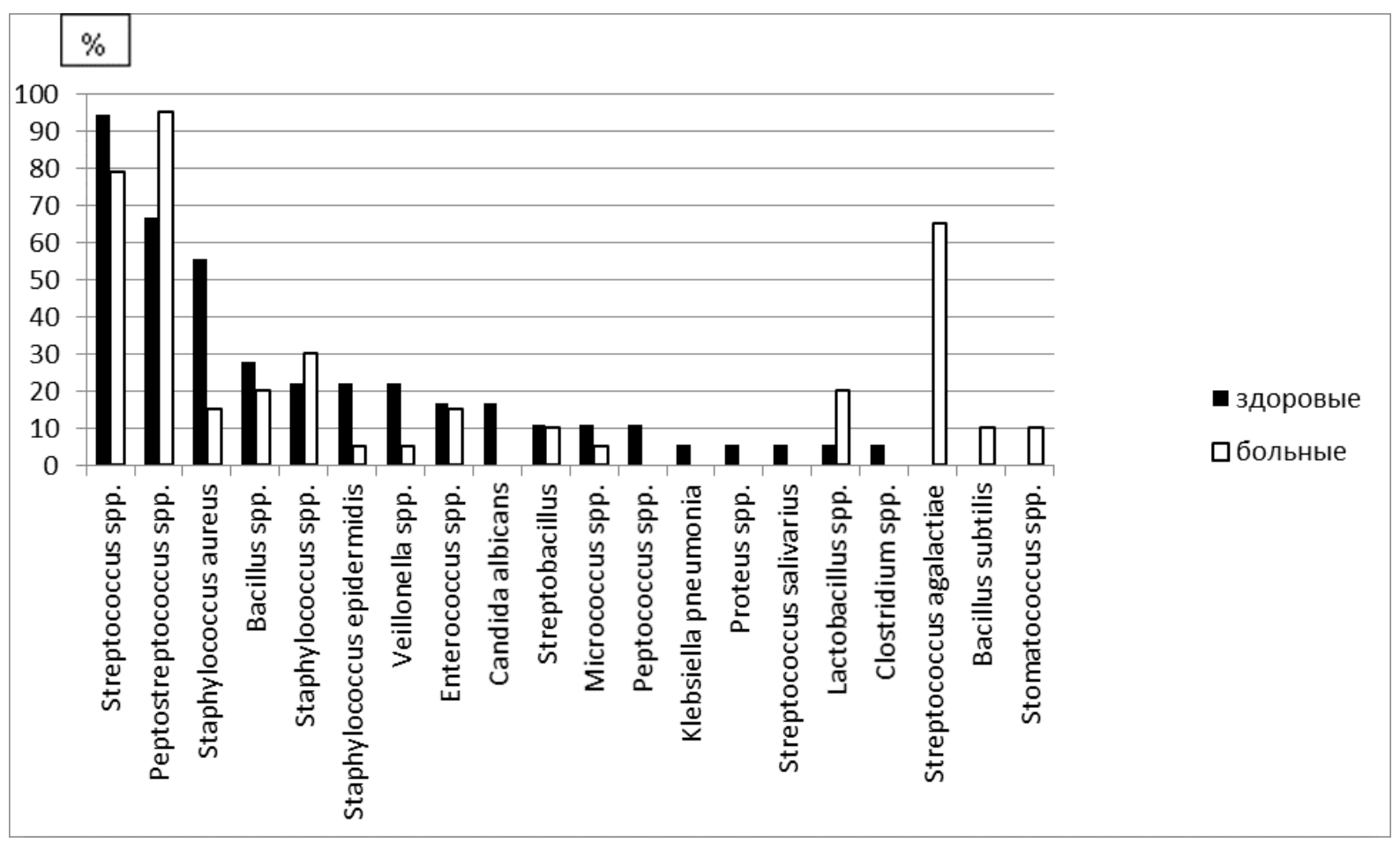

Рис. 2. Сравнительный анализ спектра и частоты встречаемости микроорганизмов соскоба с языка здоровых исследуемых и больных с пародонтитом. *- данные статистически значимы $(p<0,05)$

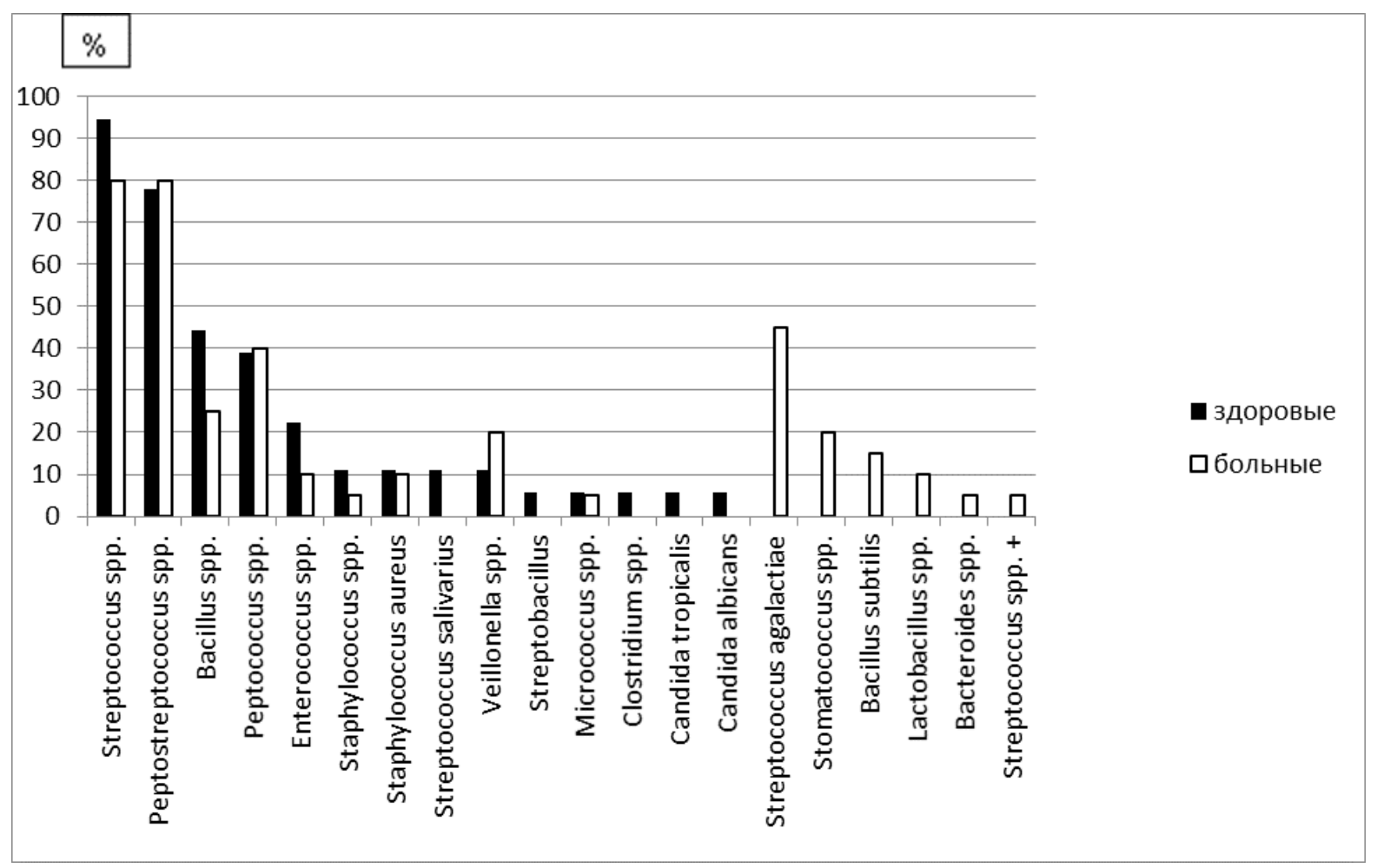

Рис. 3. Сравнительный анализ спектра и частоты встречаемости микроорганизмов зубодесневого желобка здоровых исследуемых и больных с пародонтитом. *- данные статистически значимы $(p<0,05)$ 


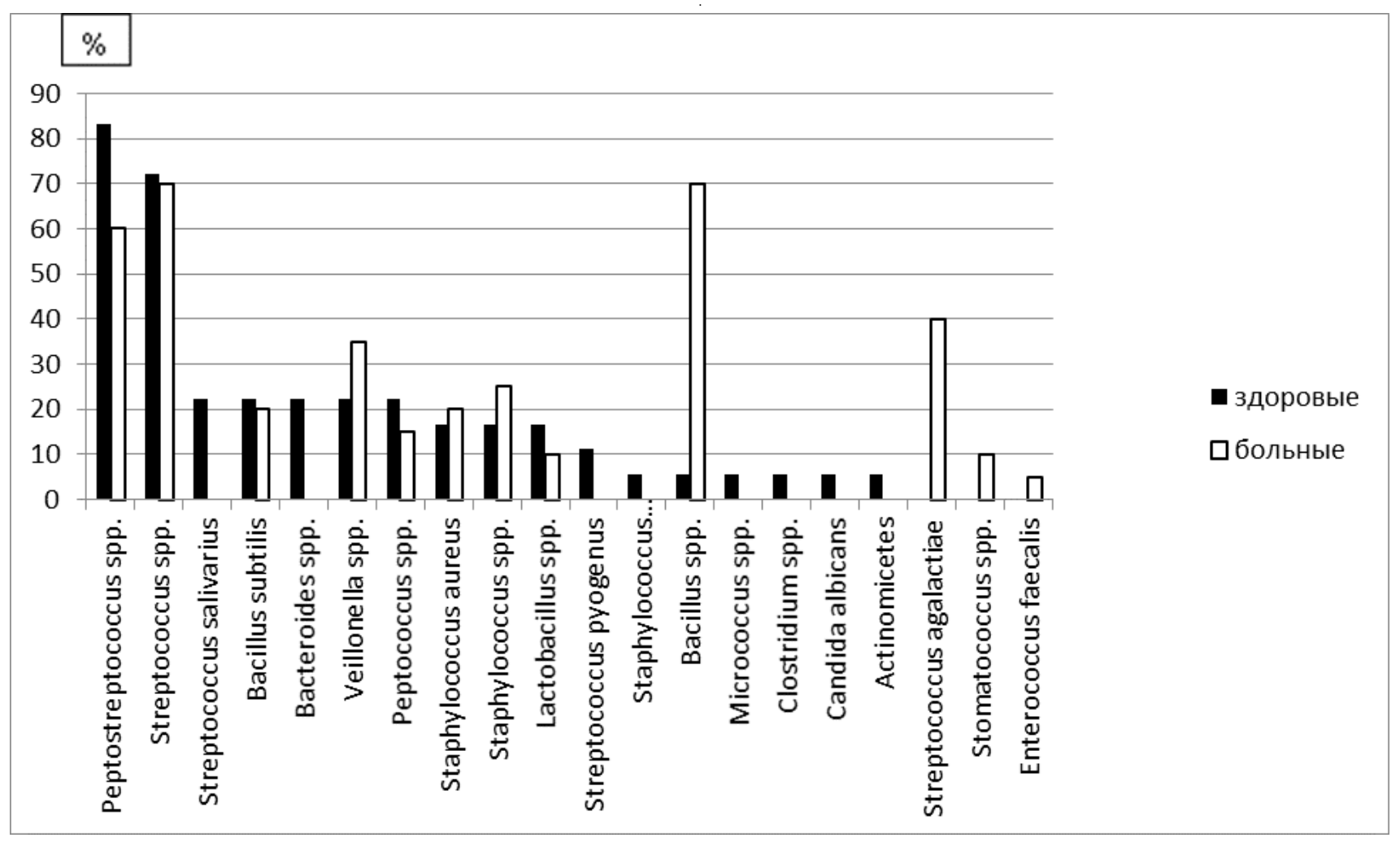

Рис. 4. Сравнительный анализ спектра и частоты встречаемости микроорганизмов ротовой жидкости здоровых исследуемых и больных с пародонтитом. *- данные статистически значимы $(p<0,05)$

Micrococcus spp., Clostridium spp., Candida albicans, Candida tropicalis встречались в менее $10 \%$.

Всодержимомпародонтальногокарманабольныхпародонтитом (рис. 3) в 80\% случаев выявлены Streptococcus spp., Peptostreptococcus spp., Streptococcus agalactiae - в 45\%, Peptococcus spp.— - 40\%, Bacillus spp. - в 25\%, Veillonella spp., Stomatococcus spp.в 20\%, Bacillus subtilis - в 15\%. Остальные микроорганизмы, Enterococcus spp., Staphylococcus aureus, Lactobacillus spp., Staphylococcus spp., Micrococcus spp., Bacteroides spp. встречались в $\leq 10 \%$ случаев.

В ротовой жидкости у здоровых людей (рис. 4) в 83,3\% случаев выявлены Peptostreptococcus spp., Streptococcus spp.— в 72,2\%, Streptococcus salivarius, Bacillus subtilis, Bacteroides spp., Veillonella spp., Peptococcus spp.- в 22,2\%, Staphylococcus aureus, Staphylococcus spp., Lactobacillus spp.- в 16,7\%, Streptococcus pyogenes - в 11,1\%. Остальные микроорганизмы, Staphylococcus epidermidis, Bacillus spp., Micrococcus spp., Clostridium spp., Candida albicans, Actinomicetes встречались в менее 10\%.

Из ротовой жидкости у больных пародонтитом (рис. 4) выделялись Streptococcus spp., Bacillus spp. - в 70\% случаев, Peptostreptococcus spp.- в 60\%, Streptococcus agalactiae - в 40\%, Veillonella spp.в 35\%, Staphylococcus spp. - в 25\%, Bacillus subtilis, Staphylococcus aureus - 20\%, Peptococcus spp.в 15\%. Остальные микроорганизмы, Lactobacillus spp., Stomatococcus spp.- в 10\%, Enterococcus faecalis встречались в менее 10\%.

Количество микроорганизмов в зубном налёте здоровых исследуемых было высоким (от 3,1 до 5,17 Ig KOЕ/мл) у Bacteroides spp. (максимальное 5,17), Streptococcus spp., Peptostreptococcus spp., Bacillus spp., Peptococcus spp., Veillonella spp., Streptococcus pyogenes, Enterococcus spp., Klebsiella pneumonia. У остальной микробиоты количество было ниже $3 \mathrm{lg}$ КОЕ/мл (Staphylococcus spp., Staphylococcus aureus, Micrococcus spp., Staphylococcus epidermidis, Streptococcus salivarius, Bacillus subtilis). Количество микроорганизмов в зубном налёте больных пародонтитом в зубном налёте было высоким (от 3 до 4,17 Ig KOE/мл) у Enterococcus spp. (максимальное 4,17), Streptococcus spp., Peptostreptococcus spp., Bacillus spp., Peptococcus spp., Veillonella spp., Streptococcus salivarius, Candida albicans, Streptococcus agalactiae. У остальной микробиоты количество было ниже $3 \mathrm{lg}$ КОЕ/мл (Lactobacillus spp., Stomatococcus 
spp. Klebsiella pneumonia, Staphylococcus spp., Staphylococcus aureus, Staphylococcus epidermidis, Bacillus subtilis).

Количество микроорганизмов из соскоба языка здоровых исследуемых было высоким (от 3,4 до 5,18 lg KOE/ мл) у Streptococcus salivarius (максимальное 5,18), Peptostreptococcus spp., Veillonella spp., Enterococcus spp., Micrococcus spp., Bacillus spp., Lactobacillus spp. У остальной микробиоты количество было ниже $3 \mathrm{lg}$ КОЕ/мл (Streptococcus spp., Clostridium spp., Staphylococcus spp., Peptococcus spp., Klebsiella pneumonia, Staphylococcus aureus, Candida albicans, Staphylococcus epidermidis, Proteus spp). Количество микроорганизмов из соскоба языка больных пародонтитом было высоким (от 3 до 4,17 lg KOЕ/мл) у Peptostreptococcus spp. u Veillonella spp. (максимальное 4,17), Streptococcus agalactiae, Streptococcus spp., Bacillus spp., Bacillus subtilis, Staphylococcus epidermidis, Lactobacillus spp. У остальной микробиоты количество было ниже $3 \mathrm{lg}$ KOE/мл (Stomatococcus spp., Enterococcus faecalis, Staphylococcus aureus, Staphylococcus spp., Enterococcus spp., Micrococcus spp.).

Количество микроорганизмов из зубодесневого желобка здоровых исследуемых было высоким (от 3 до 4,8 lg KOЕ/мл) у Peptostreptococcus spp. (максимальное 4,8), Streptococcus spp., Veillonella spp., Bacillus spp., Micrococcus spp., Streptococcus salivarius, Enterococcus spp., Clostridium spp., Peptococcus spp. У остальной микробиоты количество было ниже $3 \mathrm{lg}$ КОЕ/мл (Candida tropicalis, Staphylococcus aureus, Staphylococcus spp., Candida albicans). Количество микроорганизмов в пародонтальном кармане больных пародонтитом было высоким (от 3 до 4,17 lg KOE/ мл) у Enterococcus spp. и Bacteroides spp. (максимальное 4,17), Peptostreptococcus spp., Veillonella spp., Streptococcus spp., Peptococcus spp., Lactobacillus spp., Streptococcus agalactiae, Stomatococcus spp., Micrococcus spp. У остальной микробиоты количество было ниже $3 \mathrm{lg}$ KOE/мл (Stomatococcus spp., Staphylococcus aureus, Staphylococcus spp., Bacillus subtilis).

Количество микроорганизмов было выявлено самым высоким в ротовой жидкости как здоровых исследуемых (от 4,53 до 7,9 lg KOЕ/мл), так и больных пародонтитом (от 5,2 до 7,5 lg KOE/мл). У здоровой группы в максимальном количественном отношении можно выделить Staphylococcus spp. (7,9 lg КОЕ/мл), Streptococcus spp. (7,6 lg КОЕ/мл), Bacteroides spp. (7 lg KOE/мл), Peptostreptococcus spp. (6,8 lg KOЕ/мл). У больных пародонтитом в максимальном количественном отношении можно выделить Streptococcus agalactiae (7,5 lg КОЕ/мл), Streptococcus spp. (7 lg KOE/ мл), Peptococcus spp. (6,9 lg КОЕ/мл).

\section{Обсужление результатов}

В содержимом зубного налёта больных пародонтитом, по сравнению со здоровыми людьми, увеличивается встречаемость Peptococcus spp.- в 3,6 раза $(\mathrm{p}=0,048)$, Staphylococcus spp. u Bacillus spp.- в 1,8 раза, а также незначительно Staphylococcus aureus, Peptostreptococcus spp. и Veillonella spp (в 1,35-1,1 раза). У людей 1 группы в 1,5-1,1 раза реже изолировались Enterococcus spp., Streptococcus spp., Klebsiella pneumoniae, Staphylococcus epidermidis, Streptococcus salivarius, Bacillus subtilis. Отмечено появление Streptococcus agalactiae (в 50\% случаев и в количестве $3 \mathrm{lg}$ KOЕ/мл), Stomatococcus spp. (в 5\% случаев и в количестве 2,63 lg КОЕ/мл), Lactobacillus spp. (в 5\% случаев и в количестве $2,17 \mathrm{lg}$ KOЕ/мл) и Candida albicans (в 5\% случаев и в количестве 3,24 lg KOE/мл). У больных пародонтитом, по сравнению со здоровыми людьми увеличивается количество Streptococcus salivarius в 2 раза ( $p<0,001)$, Staphylococcus epidermidis - в 1,61 раза, Bacillus subtilis - в 1,53 раза, Enterococcus spp. - в 1,33 раза $(\mathrm{p}<0,001)$. Было отмечено уменьшение количества Klebsiella pneumoniae в 1,8 раза, Staphylococcus spp. - в 1,3 раза.

В соскобе с языка больных пародонтитом, по сравнению со здоровыми людьми, в 4,4 раза реже изолируются Staphylococcus epidermidis и Veillonella spp., Staphylococcus aureus - в 3,7 раза $(\mathrm{p}=0,01)$, Micrococcus spp.- в 2,2 раза, Bacillus spp.- в 1,4 раза, Streptococcus spp.- в 1,2 раза, Enterococcus spp.- в 1,1 раза. У людей 1 группы при сравнении с здоровыми в 3,6 раза чаще выявлялись Lactobacillus spp., в 1,4 раза $(\mathrm{p}=0,032)$ - Peptostreptococcus spp., в 1,35 раза Staphylococcus spp. У больных ХГП отмечено появление Streptococcus agalactiae в 65\% случаев и в количестве 4,1 lg KOЕ/мл. В соскобе с языка больных пародонтитом, по сравнению со здоровыми людьми увеличивается количество Staphylococcus epidermidis в 1,46 раза, Streptococcus spp. - в 1,42 раза. ( $<<0,001)$. Уменьшалось количество Enterococcus spp. в 1,8 раза ( $\mathrm{p}<0,001)$, Micrococcus spp.— в 1,6 раза.

В содержимом пародонтального кармана больных пародонтитом, по сравнению с зубодесневым желобком здоровых людей увеличивается встречаемость Veillonella spp. - в 1,8 раза. При этом у людей опытной группы в 2,2 раза реже изолировались Enterococcus spp. и Staphylococcus spp., Bacillus spp.- в 1,8 раза, Streptococcus spp.- в 1,2 раза. Появились Streptococcus agalactiae в 45\% случаев, Stomatococcus spp.- в 20\% случаев, Bacillus 
subtilis- в 15\% случаев, Lactobacillus spp.- в 10\% случаев. В содержимом пародонтального кармана больных пародонтитом, по сравнению со здоровыми людьми увеличивается количество Enterococcus spp. в 1,35 раза $(\mathrm{p}<0,001)$. У людей из 1 группы практически не изменялось количество Staphylococcus aureus $(\mathrm{p}<0,001)$, Peptococcus spp., Staphylococcus spp., Bacillus spp. $(\mathrm{p}=0,044)$, Streptococcus spp. $(\mathrm{p}=0,041)$, Peptostreptococcus spp. $(\mathrm{p}<0,001)$, Micrococcus spp., Veillonella spp. Отмечено появление Lactobacillus spp.- 3,3 lg KОЕ/мл, Streptococcus agalactiae - 3,2 lg КОЕ/мл, Stomatococcus spp.- 2,5 lg КОЕ/мл, Bacillus subtilis - 2,16 lg КОЕ/мл.

В ротовой жидкости больных пародонтитом по сравнению со здоровой группой происходит увеличение встречаемости Bacillus spp.- в 12,6 раз ( $\mathrm{p}<0,001)$, Veillonella spp.- в 1,6 раза, Staphylococcus spp.в 1,5 раза, Staphylococcus aureus - в 1,2 раза. При этом у людей 1 группы в 1,7 раза реже изолировались Lactobacillus spp., в 1,5 раза-Peptococcus spp., в 1,4 раза-Peptostreptococcus spp. У больных ХГП отмечено появление Streptococcus agalactiae - в 40\% случаев, Stomatococcus spp.- в 10\% случаев, Enterococcus faecalis.- в 5\% случаев. В ротовой жидкости больных пародонтитом практически не изменяется количество Bacillus spp., Peptococcus spp., Veillonella spp., Bacillus subtilis, Staphylococcus spp. $(\mathrm{p}<0,001)$, Bacteroides spp., Streptococcus spp., Staphylococcus aureus, Lactobacillus spp. Появлялись Streptococcus agalactiae в количестве 7,5 lg KOЕ/мл, Enterococcus faecalis - 6,17 lg КОЕ/мл, Stomatococcus spp. - 5,2 lg $\mathrm{KOE} / \mathrm{мл}$.

\section{Выво $\triangle \mathrm{b}$}

У жителей Тверского региона с хроническим генерализованным пародонтитом в период ремиссии не вы- явлен значительный микробный дисбаланс ни в одном из биотопов. Во всех биотопах отмечено появление Streptococcus agalactiae 40-65\% случаев $(\mathrm{p}=0,003)$ и в количестве $3-7,5 \mathrm{lg} \mathrm{KOE} / \mathrm{M}$ ( $(\mathrm{p}=0,024)$.

В язычном налете, обнаружено уменьшение частоты встречаемости стафилококков, S. aureus, $S$. epidermidis, и значительное увеличение встречаемости бактерий рода Lactobacillus. В содержимом зубного налёта отмечено увеличение частоты встречаемости бактерий родов Peptococcus и Staphylococcus, а также появление только у больных людей Lactobacillus spp., Streptococcus agalactiae $u$ Candida albicans, что может повышать ацидогенный потенциал в данном биотопе. В содержимом пародонтального кармана у людей, больных пародонтитом, отмечено увеличение встречаемости Veillonella spp., Peptostreptococcus spp. и Peptococcus spp., а также двухкратным уменьшением встречаемости Staphylococcus spp. В ротовой жидкости у людей, больных пародонтитом отмечено значительное увеличение встречаемости только Bacillus spp. (в 12,6 раза), а также незначительное увеличение Veillonella spp., Staphylococcus spp., Staphylococcus aureus (в 1,6-1,2 раза).

Особенностью микробиоты исследованных биотопов больных хроническим генерализованным пародонтитом является отсутствие типичных пародонтопатогенов: «красного комплекса» - P.gingivalis, T.denticola, «оранжевого комплекса»-Campylobacter spp., «зелёного комплекса»- Capnocytophaga spp., Eikenella corrodens. С другой стороны, выявлен явный дисбаланс между резидентной и условно-патогенной микробиотой. Данные изменения нуждаются в про- и пребиотической микробиологической коррекции с целью удлинения периодов ремиссии и купирования воспалительных изменений в тканях пародонта.

\section{ЛИТЕРАТУРА}

1. Oral microbiota: A new view of body health / Maoyang Lu, Song Xuan, Zhao Wang. // Food Science and Human Wellness. 2019; 8(1): 8-15

2. Биоплёнки патогенных бактерий: биологические свойства и роль в хронизации инфекционного процесса / Харсеева Г.Г., Миронов А.Ю., Фролова Я.Н. // Успехи современной биологии. - 2015. - т. 135, № 4. - С. 346-354.

3. Чепуркова 0.А., Чеснокова М.Г., Недосеко В.Б., Миронов А.Ю. Кандида-ассоциированный пародонтит. Диагностика. Лечение: Монография / Омск: «Вариант-Омск», 2012. 160 c.

4. Characterization of a signaling system in the oral commensal Streptococcus mitis that mediates interspecies communication with the pathogen Streptococcus pneumonia / R. Junges, K. Sturød, G. Salvadori, H.A. Åmdal, T. Chen, F.C. Petersen // Appl. Environ. Microbiol. 2019; 85(2): e02297-18

5. Oral Biofilms: Development, Control, and Analysis / Berger D, Rakhamimova A, Pollack A, Loewy Z // High Throughput. 2018;7(3):24.

6. Consistent and reproducible long-term in vitro growth of health and disease-associated oral subgingival biofilms / Velsko IM, Shaddox LM // BMC Microbiol. 2018;18(1):70.

7. Микробиоценозы полости рта у больных генерализованным пародонтитом и их коррекции / Лебедев Д.В., Червинец В.М., Миронов А.Ю., Червинец Ю.В. // Стоматолог. 2011. - № 12. - С. 23-29.

8. Genetic Association with Subgingival Bacterial Colonization in Chronic Periodontitis / Cavalla F, Biguetti CC, Melchiades JL, et al. // Genes (Basel). $2018 ; 9$ (6):271. 
9. The role of natural salivary defences in maintaining a healthy oral microbiota / Anne Marie Lynge Pedersen, Daniel Belstrøm. // Journal of Dentistry. 2019; 80(1): 3-12

10. Comparison of Subgingival and Buccal Mucosa Microbiome in Chronic and Aggressive Periodontitis: A Pilot Study / Wei Y, Shi M, Zhen M, et al. // Front Cell Infect Microbiol. 2019; 9:53.

11. Relative abundance of total subgingival plaque-specific bacteria in salivary microbiota reflects the overall periodontal condition in patients with periodontitis / Kageyama S, Takeshita T, Asakawa M, et al. // PLoS One. 2017;12(4): e0174782.

( Червинец Вячеслав Михайлович ( chervinets@mail.ru ), Червинец Юлия Вячеславовна ( julia_chervinec@mail.ru ),

Леонтьева Аурелия Валерьевна ( aurica171900@mail.ru ), Беляев Всеволод Станиславович ( seva.belyaev.99@mail.ru ),

Стулов Никита Михайлович ( nikita888033@mail.ru ), Родионов Андрей Александрович ( andrew.rodionov@tvergma.ru),

Червинец Алина Вячеславовна ( lina555_90@mail.ru ),Трошин Андрей Валерьевич ( bravostom@mail.ru ),

Румянцев Виталий Анатольевич ( rumyancev_v@tvergma.ru ).

Журнал «Современная наука: актуальные проблемы теории и практики»

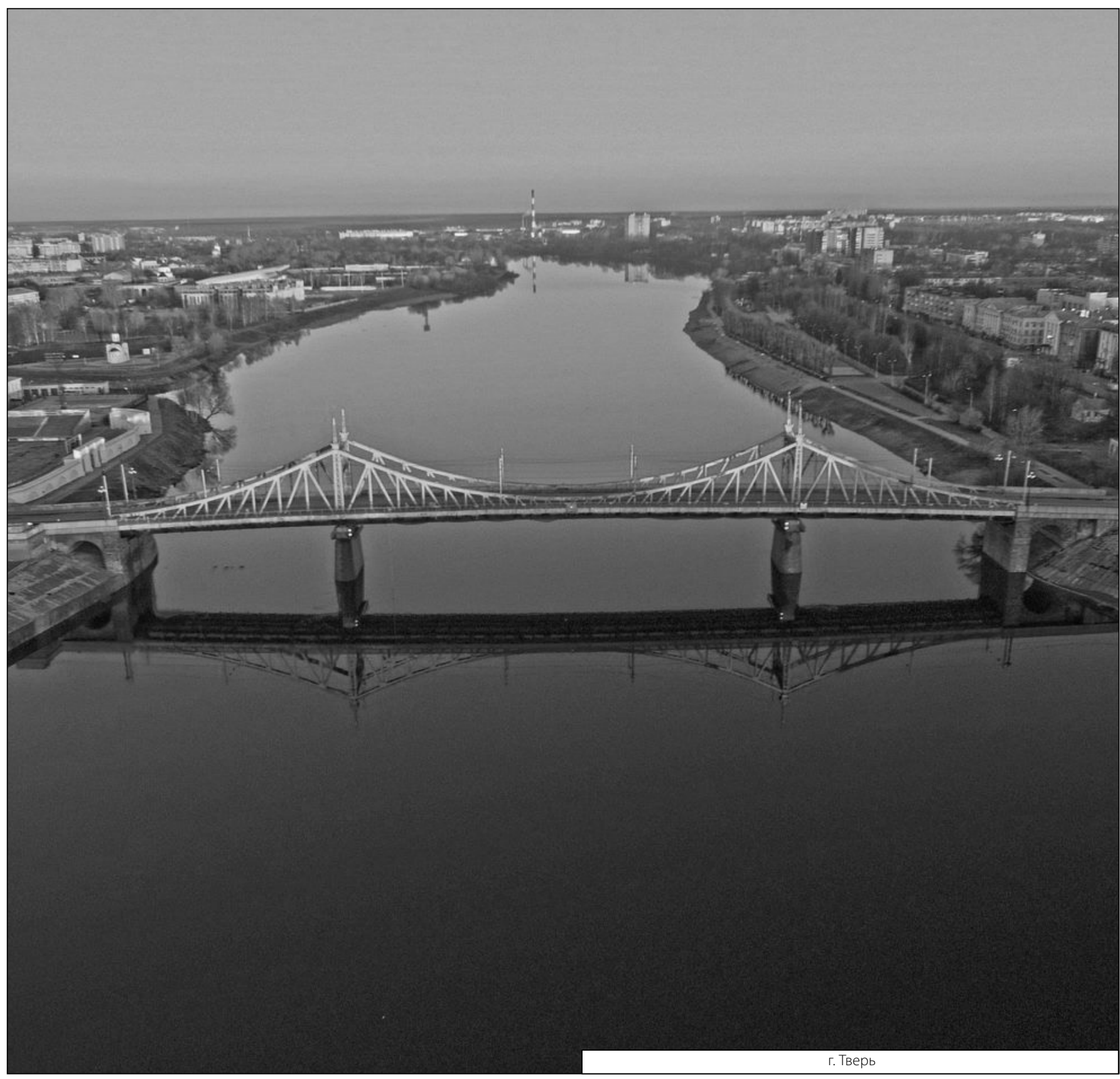

